\title{
Epidemiology of neonatal infections in hospitals of Nepal: evidence from a large- scale study
}

Shyam Sundar Budhathoki ${ }^{1,2} \mathbb{D}$, Avinash K. Sunny ${ }^{1} \mathbb{D}$, Pragya Gautam Paudel ${ }^{1}$, Jeevan Thapa ${ }^{3}$,

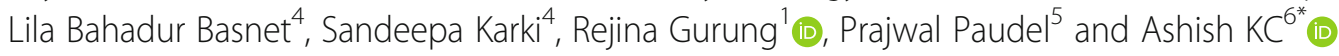

\begin{abstract}
Background: Every year, neonatal infections account for approximately 750,000 neonatal deaths globally. It is the third major cause of neonatal death, globally and in Nepal. There is a paucity of data on clinical aetiology and outcomes of neonatal infection in Nepal. This paper aims to assess the incidence and risk factors of neonatal infection in babies born in public hospitals of Nepal.

Methods: This is a prospective cohort study conducted for a period of 14 months, nested within a large-scale cluster randomized control trial which evaluated the Helping Babies Breathe Quality Improvement package in 12 public hospitals in Nepal. All the mothers who consented to participate within the study and delivered in these hospitals were included in the analysis. All neonates admitted into the sick newborn care unit weighing $>1500 \mathrm{~g}$ or/and 32 weeks or more gestation with clinical signs of infection or positive septic screening were taken as cases and those that did not have an infection were the comparison group. Bivariate and multi-variate analysis of sociodemographic, maternal, obstetric and neonatal characteristics of case and comparison group were conducted to assess risk factors associated with neonatal infection.

Results: The overall incidence of neonatal infection was 7.3 per 1000 live births. Babies who were born to first time mothers were at $64 \%$ higher risk of having infection (aOR-1.64, 95\% Cl, 1.30-2.06, $p$-value $<0.001$ ). Babies born to mothers who had no antenatal check-up had more than three-fold risk of infection (aOR-3.45, 95\% Cl, 1.82-6.56, $p$-value< 0.001). Babies born through caesarean section had more than two-fold risk (aOR-2.06, 95\% Cl, 1.48-2.87, $p$-value< 0.001 ) and babies with birth asphyxia had more than three-fold risk for infection (aOR-3.51, 95\% Cl, 1.71-7.20, p-value $=0.001$ ).

Conclusion: Antepartum factors, such as antenatal care attendance, and intrapartum factors such as mode of delivery and birth asphyxia, were risk factors for neonatal infections. These findings highlight the importance of ANC visits and the need for proper care during resuscitation in babies with birth asphyxia.
\end{abstract}

Keywords: In-patient neonatal infection, Antenatal check-up, Caesarean section, Birth asphyxia, Risk factor, Nepal

\footnotetext{
* Correspondence: aaashis7@yahoo.com

${ }^{6}$ Department of Women's and Children's Health, Uppsala University, Dag Hammarskjölds väg 14B, Uppsala, Sweden

Full list of author information is available at the end of the article
}

C The Author(s). 2020 Open Access This article is licensed under a Creative Commons Attribution 4.0 International License, which permits use, sharing, adaptation, distribution and reproduction in any medium or format, as long as you give appropriate credit to the original author(s) and the source, provide a link to the Creative Commons licence, and indicate if changes were made. The images or other third party material in this article are included in the article's Creative Commons licence, unless indicated otherwise in a credit line to the material. If material is not included in the article's Creative Commons licence and your intended use is not permitted by statutory regulation or exceeds the permitted use, you will need to obtain permission directly from the copyright holder. To view a copy of this licence, visit http://creativecommons.org/licenses/by/4.0/. The Creative Commons Public Domain Dedication waiver (http://creativecommons.org/publicdomain/zero/1.0/) applies to the data made available in this article, unless otherwise stated in a credit line to the data. 


\section{Background}

In 2018 the global neonatal death rate was 18 per 1000 live births, accounting for 2.5 million neonatal deaths [1]. This represents approximately 7000 neonatal deaths every day [1]. Among under five mortalities, more than two-fifth of deaths occur during the neonatal period and one third of these neonatal deaths are due to infection [2]. Among these deaths, 25\% occur in South Asia and sub-Saharan Africa [2].

Neonatal infection is manifested by systemic signs of infection and isolation of a bacterial or other pathogen from the bloodstream [3, 4]. Infection in newborn increases the risk of developing neurodevelopmental impairments such as delayed gross motor, language and cognitive skills later in pre-school life [5-7]. Compared to high income countries, low-and middle-income countries (LMICs) have approximately 40 times higher incidence rates of neonatal infection and double the mortality rates [2, 3]. However, there is limited population-based evidence available from low-income countries and a lack of standardised diagnostic criteria and definitions which together serve as obstacles to accurate estimation of the global burden of neonatal infections [3].

Nepal aims to reduce neonatal mortality rate to 12 per 1000 live birth or less by 2030 as part of the target set by the Sustainable Development Goal for health $[8,9]$. Between 2001 to 2016, the neonatal mortality rate in Nepal declined from 39 to 21 deaths per thousand [10]. However, Neonatal infection is one of the leading causes of hospital admissions and neonatal deaths in Nepal [11-13]. The prevalence of neonatal infections ranges between 2 and $4 \%$ in Nepal [12], with $37.1 \%$ of infections occurring in neonatal intensive care units of tertiary referral hospital [11]. Previous study on exploring trends and determinants of neonatal mortality in Nepal identified several risk factors of neonatal mortality in Nepal [10]. These risk factors include lack of education, less than four antenatal care visits, babies born with less than two-year birth intervals and mother's exposure to indoor air pollution [10].

In Nepal, maternal and newborn health service is delivered through three tier approach [14, 15]. Primary health care center provides routine antenatal care service, normal vaginal delivery and basic newborn care. District or secondary level hospital provide basic emergency obstetric services and in-patient management of sick newborns. Regional or tertiary level hospital provide comprehensive emergency obstetric services and specialized newborn care to sick newborns.

Early identification of risk factors of neonatal infections would help to select babies who need special care. This study aims to add up to the evidence of incidence and risk factors of neonatal infection in district and regional hospitals of Nepal.

\section{Methods}

\section{Study setting, design and period}

This is a prospective cohort study, nested within a largescale cluster randomized control trial which evaluated the Helping Babies Breathe Quality Improvement package in 12 public hospitals of Nepal $[16,17]$. The hospitals are mapped in Fig. 1. These hospitals are referral centres which provide obstetric, neonatal and paediatric services. The annual number of deliveries in each hospital ranged from 1194 to 11,318 . All these hospitals provided comprehensive obstetric and neonatal care services along with sick newborn care services (Additional file 1). This paper presents data from a period of 14 months from July 2017 to August 2018.

\section{Study population}

All the newborns who were born at the participating hospitals during the study period were eligible for the study. The newborns with consenting parents were enrolled in the study. All the newborns with signs of clinical infection or positive septic screening with birth weight $1500 \mathrm{~g}$ or more and/or gestational age 32 weeks or more were considered as 'cases'. All other newborns were considered as referent or comparison population. The cases were treated using antibiotics was per the national guideline [12].

\section{Study size}

All eligible cases consenting for participation were included in the study. A total of 60,400 mothers, based on the sample size required to evaluate the effect of quality improvement package for the primary study was taken for this study.

\section{Data sources/measurement}

Information on newborn were obtained from data collectors who were assigned to the maternity ward in each hospital. A data retrieval form was used to extract clinical information on mothers and newborn from the patient records and register. A semi-structured interview with mothers were conducted to assess information on their socio-demographic characteristics and antenatal care.

\section{Data management and statistical methods}

After the completion of recording and interviews, forms were assessed by the data coordinator in each site for completeness. To ensure the accuracy of the data collected, $10 \%$ of the mothers' information were recollected by the data coordinator. At the end of each day, the information sheets were indexed by the data coordinator. Every week completed forms were sealed in an opaque envelope and sent to the Kathmandu office for further data management. In the Kathmandu office, these forms were reassessed for completeness and open-ended questions were recoded. Data entry was done in CS pro (Census and 


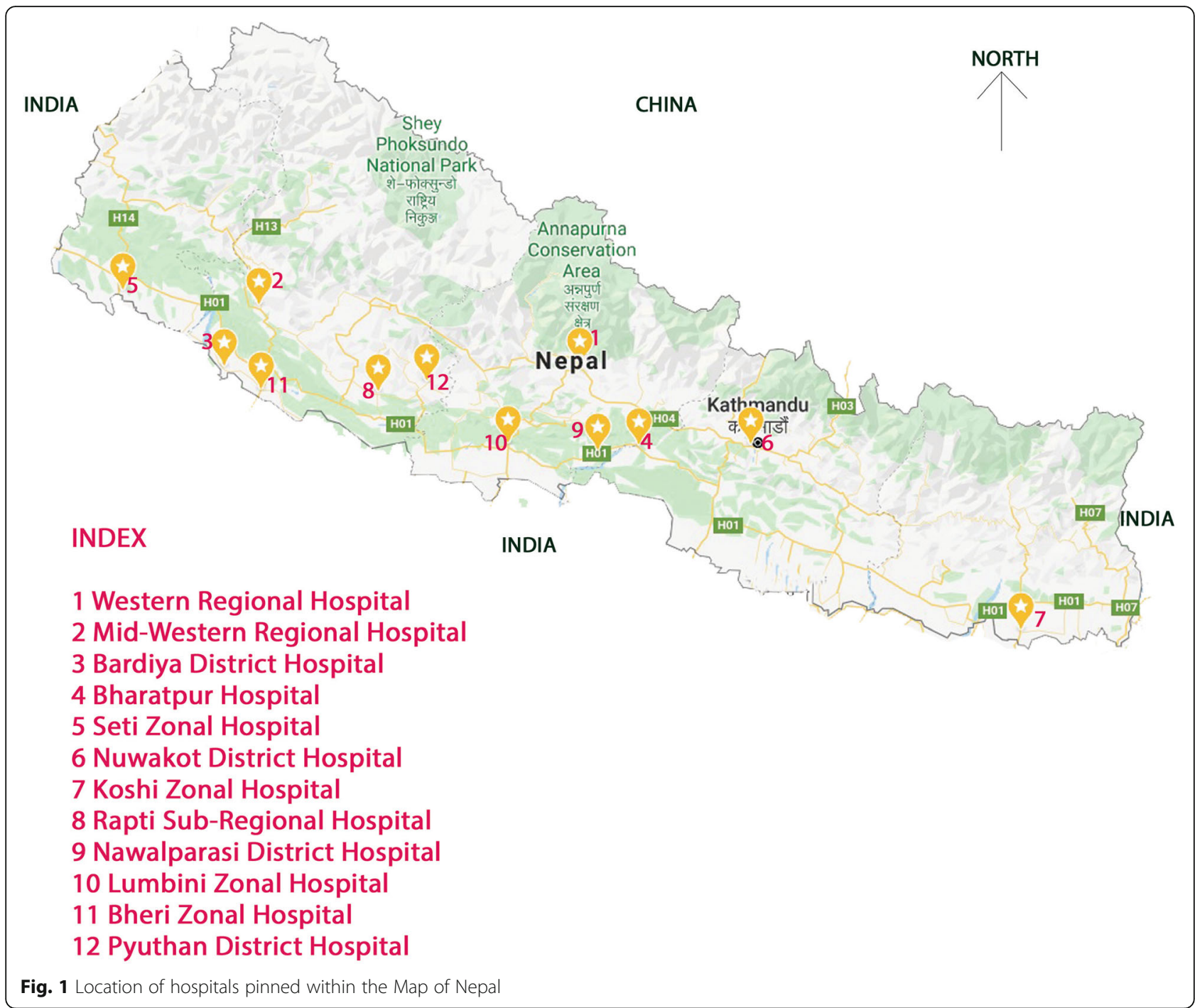

Survey Processing System) database and $5 \%$ of data were re-entered to assess the accuracy of data entry. Every month the data were entered into a data entry platform, CS pro. Finally, the data were exported to SPSS (Statistical Package for the Social Sciences) for statistical analysis.

To ensure the privacy and safety of the data, the exported data were stored in an external hard drive. Prior to data analysis, anonymization and removal of location of the participants was ensured. All hard copies of information sheets were indexed and stored as per the ethical guideline.

\section{Study variables}

Socio-demographic, maternal, obstetric and neonatal characteristics were collected through data extraction and semi-structured interviews.

\section{Maternal age}

Maternal age was categorized as less than 20 years, 2035 years and 35 years and above.

\section{Maternal education}

Mothers who are illiterate or have received education through informal trainings other than in schools were categorised as having 'no formal education' while those who had gone to school for education were considered as having 'formal education'.

\section{Ethnicity}

was categorized as Dalit, Janjati, Madhesi, Muslim, Chettri/Brahmin, and other castes based on hierarchical caste system of Nepal [18]. Ethnicity was categorized as disadvantageous group (Dalit, Janjati and Muslim) and relatively advantageous group (Madhesi, Chettri/Brahmin and other castes). 


\section{Mothers smoking status}

Smokers were those who had a history of smoking during or before pregnancy. Non-smokers were those who never smoked in their lifetime.

\section{Indoor tobacco smoke}

Environmental tobacco smoke (ETS), also referred to as second hand smoke, is a mixture of exhaled mainstream smoke (MS) and side stream smoke (SS) released from the smouldering tobacco product [19],

\section{Parity}

Mothers who had no previous births (nulliparity), at least one or more previous birth (primiparity and multiparity),

\section{Antenatal check-up}

Mothers who received antenatal care (ANC) check-up from a skilled provider,

\section{Four antenatal check-up}

Mothers who received at least four ANC check-ups from a skilled provider or less than four check-ups,

\section{Severe anaemia during pregnancy}

Serum haemoglobin less than $7.0 \mathrm{~g} /$ decilitre,

\section{Suspected maternal infections}

Mothers who received prophylactic antibiotics for a suspected infection,

\section{Mode of delivery}

Mothers who gave birth vaginally or through caesarean section.

\section{Gender of the baby}

The sex of the baby as male or female.

\section{Weight of the baby}

Birth weight categorized as less than 2500 g, 2500-4000 $\mathrm{g}$ or $4000 \mathrm{~g}$ and more.

\section{Gestational age}

Gestational age is calculated using the last menstrual period and categorized as less than 37 weeks, 37-42 weeks or 42 weeks and more.

\section{Immediate breast feeding}

Breast feeding within $1 \mathrm{~h}$ of birth.

\section{Applied antiseptic to umbilical cord stump}

Application of antiseptic to the umbilical cord.

\section{Multiple birth}

Mother delivered two or more babies.

\section{Birth asphyxia}

Birth asphyxia was defined as APGAR score of less than 6 at $1 \mathrm{~min}$ or/and APGAR score of less than 6 at $5 \mathrm{~min}$.

\section{Data analysis}

The incidence of neonatal infection was calculated with $95 \%$ confidence interval (CI) by socio-demographic characteristics (maternal age, maternal education, ethnicity, smoking and indoor pollution), maternal characteristics (parity, antenatal checkup and severe anemia), obstetric and neonatal characteristics (suspected maternal infection, mode of delivery, gender of baby, birth weight, gestational age, breast feeding, applied antiseptic to umbilical cord, multiple birth and birth asphyxia). The variables among the socio-demographic, maternal, obstetric and neonatal characteristics for neonatal infection with 95\% CI higher than the comparator group with $p<0.05$ were included within bi-variate logistic regression. Variables included within the bi-variate analysis with a $p$ value $<0.01$ were subsequently included within the multi-variate analysis. Crude odds ratios were calculated from bi-variate analysis and adjusted odds ratio were calculated from multi-variate analysis.

Missing variables were excluded from the analysis.

\section{Results}

A total of 63,099 pregnant women were admitted to the selected hospitals with 60,742 having delivered during the study period. Of those, 60,062 babies were eligible for the study and 441 of them were admitted as Neonatal infection (Fig. 2).

Incidence of Neonatal infection was high among babies of advantageous ethnic group (0.9, 95\% CI, 0.8-1.0) in comparison with babies of disadvantageous ethnic group (0.6, 95\% CI, 0.6-0.7). The incidence was higher among babies born from mothers who had given birth for the first time $(0.9,95 \% \mathrm{CI}, 0.8-1.0)$ than among babies of mothers who had given birth previously $(0.6,95 \%$ CI, 0.5-0.6). The incidence was also higher among babies of mothers who did not receive any antenatal check-ups by skilled providers $(2.1,95 \%$ CI, 1.2-3.7) than babies of mothers who received antenatal check-up (0.7, 95\% CI, 0.6-0.7) (Table 1).

The incidence of neonatal infection was higher among mothers who had suspected infection $(1.3,95 \% \mathrm{CI}, 1.1-$ 1.5) than those who did not have suspected infection (0.6, 95\% CI, 0.6-0.7). Babies who were born through caesarean section (CS) showed a higher incidence of infection (1.3, 95\% CI, 1.1-1.5) than babies born via vaginal delivery $(0.6,95 \% \mathrm{CI}, 0.5-0.7)$. The incidence of neonatal infection was also higher among babies who had birth asphyxia $(2.7,95 \% \mathrm{CI}, 1.5-4.7)$ than those who did not have birth asphyxia (Table 2). 


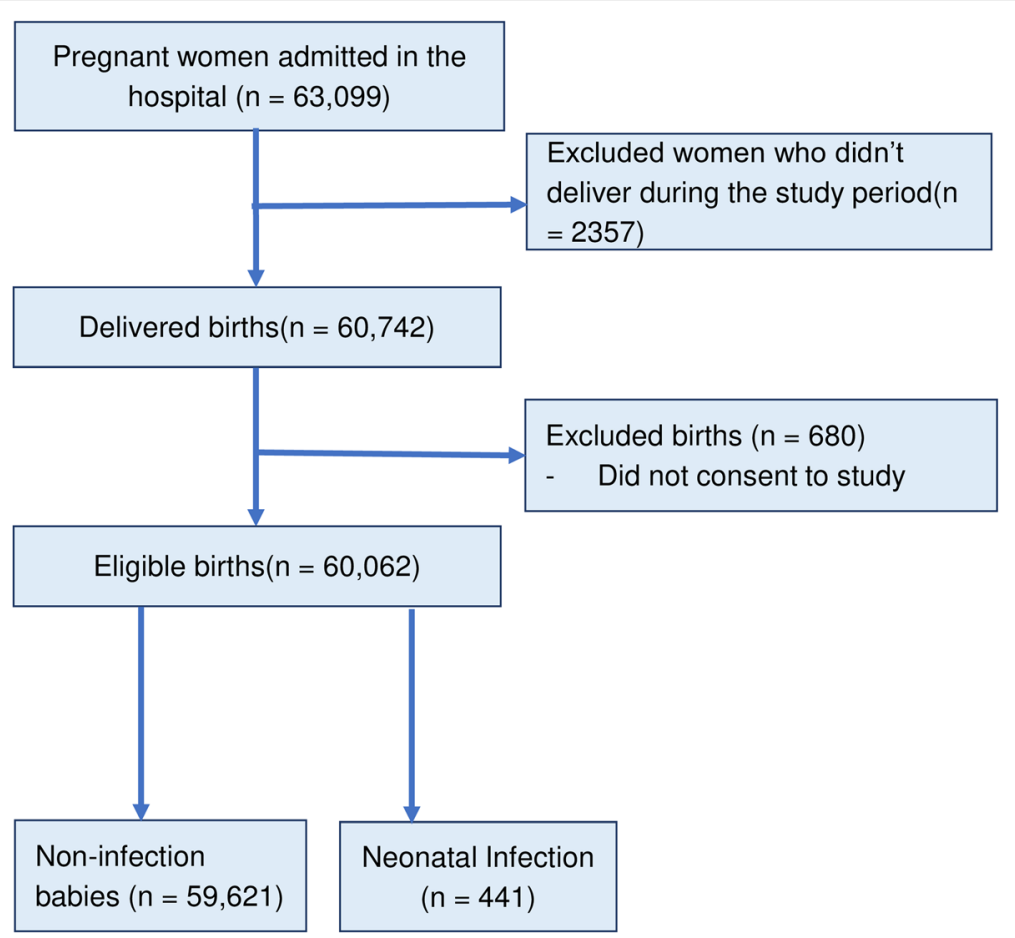

Fig. 2 Study flow diagram

Table 1 Incidence of neonatal infection by socio-demographic and maternal characteristics

\begin{tabular}{|c|c|c|c|c|}
\hline \multirow{2}{*}{$\begin{array}{l}\text { Socio-demographic and maternal characteristics } \\
\text { Maternal age }\end{array}$} & \multicolumn{2}{|c|}{ Neonatal infection } & \multirow[t]{2}{*}{ Incidence $(95 \% \mathrm{Cl})$} & \multirow[t]{2}{*}{$p$-value } \\
\hline & No & Yes & & \\
\hline Less than 20 years & 8346 & 57 & $0.7 \%(0.5-0.9)$ & 0.621 \\
\hline $20-35$ years & 50,176 & 370 & $0.7 \%(0.7-0.8)$ & \\
\hline More than 35 years & 1540 & 14 & $0.9 \%(0.5-1.5)$ & \\
\hline \multicolumn{5}{|l|}{ Maternal education ${ }^{\mathrm{a}}$} \\
\hline No formal education & 7863 & 61 & $0.8 \%(0.6-1.0)$ & 0.309 \\
\hline Formal education & 42,521 & 286 & $0.7 \%(0.6-0.7)$ & \\
\hline \multicolumn{5}{|l|}{ Ethnicity } \\
\hline Advantageous group & 23,626 & 205 & $0.9 \%(0.8-1.0)$ & 0.002 \\
\hline Relatively disadvantageous group & 36,436 & 236 & $0.6 \%(0.6-0.7)$ & \\
\hline \multicolumn{5}{|l|}{ Smoking/Indoor tobacco smoke } \\
\hline Maternal smoking ${ }^{b}$ & 5679 & 26 & $0.5 \%(0.3-0.7)$ & 0.026 \\
\hline Indoor tobacco smoke ${ }^{a}$ & 12,947 & 61 & $0.5 \%(0.4-0.6)$ & 0.026 \\
\hline \multicolumn{5}{|l|}{ Parity } \\
\hline 0 previous birth & 29,564 & 267 & $0.9 \%(0.8-1.0)$ & $<0.001$ \\
\hline 1 or more previous birth & 30,498 & 174 & $0.6 \%(0.5-0.6)$ & \\
\hline \multicolumn{5}{|l|}{ Antenatal check-up ${ }^{a}$} \\
\hline No ANC & 526 & 11 & $2.1 \%(1.2-3.7)$ & $<0.001$ \\
\hline At least once & 49,858 & 336 & $0.7 \%(0.6-0.7)$ & \\
\hline \multicolumn{5}{|l|}{ Four antenatal check up } \\
\hline Less than 4 ANC & 11,542 & 61 & $0.5 \%(0.4-0.7)$ & 0.029 \\
\hline 4 or more ANC & 38,316 & 275 & $0.7 \%(0.6-0.8)$ & \\
\hline Severe maternal anemia & 167 & 1 & $0.5 \%(0.1-3.5)$ & 0.562 \\
\hline
\end{tabular}

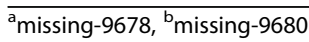


Table $\mathbf{2}$ Incidence of neonatal infection by obstetric and neonatal characteristics

\begin{tabular}{|c|c|c|c|c|}
\hline \multirow[t]{2}{*}{ Obstetric and birth characteristics } & \multicolumn{2}{|c|}{ Neonatal infection } & \multirow{2}{*}{$\begin{array}{l}\text { Incidence } \\
(95 \% \text { Cl) }\end{array}$} & \multirow[t]{2}{*}{$p$-value } \\
\hline & No & Yes & & \\
\hline \multicolumn{5}{|l|}{ Suspected maternal infection ${ }^{a}$} \\
\hline Yes & 9893 & 128 & $1.3 \%(1.1-1.5)$ & \multirow[t]{2}{*}{$<0.001$} \\
\hline No & 40,993 & 263 & $0.6 \%(0.6-0.7)$ & \\
\hline \multicolumn{5}{|l|}{ Mode of delivery } \\
\hline Vaginal & 47,059 & 276 & $0.6(0.5-0.7)$ & \multirow[t]{2}{*}{$<0.001$} \\
\hline Caesarean section & 12,492 & 160 & $1.3(1.1-1.5)$ & \\
\hline \multicolumn{5}{|l|}{ Gender } \\
\hline Boys & 32,401 & 263 & $0.8 \%(0.7-0.9)$ & \multirow[t]{2}{*}{0.016} \\
\hline Girls & 27,661 & 178 & $0.6 \%(0.5-0.7)$ & \\
\hline \multicolumn{5}{|l|}{ Birth weight } \\
\hline Less than $2500 \mathrm{~g}$ & 6659 & 57 & $0.8 \%(0.6-1.0)$ & \multirow[t]{3}{*}{0.011} \\
\hline $2500-4000 \mathrm{~g}$ & 52,067 & 366 & $0.7 \%(0.6-0.8)$ & \\
\hline $4000 \mathrm{~g}$ or more & 1336 & 18 & $1.3 \%(0.8-2.1)$ & \\
\hline \multicolumn{5}{|l|}{ Gestational age } \\
\hline Less than 37 weeks & 46 & 5569 & $0.8 \%(0.6-1.0)$ & \multirow[t]{2}{*}{0.400} \\
\hline 37 weeks or more & 395 & 54,493 & $0.7 \%(0.7-0.8)$ & \\
\hline Early breast feeding & 43,292 & 301 & $0.7 \%(0.5-0.9)$ & 0.903 \\
\hline Applied antiseptic to umbilical cord & 18,547 & 126 & $0.7 \%(0.6-0.8)$ & 0.395 \\
\hline \multicolumn{5}{|l|}{ Multiple birth } \\
\hline No & 59,698 & 437 & $0.7 \%(0.7-0.8)$ & \multirow[t]{2}{*}{0.414} \\
\hline Yes & 364 & 4 & $1.1 \%(0.4-2.9)$ & \\
\hline Birth asphyxia & 413 & 11 & $2.7 \%(1.5-4.7)$ & $<0.001$ \\
\hline
\end{tabular}

amissing-9176

Bivariate regression analysis showed that babies who were born to mothers within advantageous ethnic group had a $34 \%$ higher risk of having an infection than babies born to mothers from disadvantageous ethnic group $($ cOR-1.34, 1.11-1.62, $p$-value $=0.002)$. Babies who were born to first-time mothers had a 59\% higher risk of infection compared to primiparous or multiparous mothers (cOR-1.59, 95\% CI, 1.31-1.92, $p$-value $<0.001$ ). Babies who were born through CS had more than twofold risk of infection than those born via vaginal delivery (cOR-2.20, 95\% CI, 1.81-2.68, $p$-value<0.001). Babies who had birth asphyxia had more than three-fold risk of infection than those who did not have birth asphyxia (cOR-3,77, 95\% CI, 2.05-6.91, $p$-value< 0.001) (Table 3).

In the multi-variate analysis, babies born to mothers who had no antenatal check-up had more than threefold risk of neonatal infection (aOR-3.45, 95\% CI, 1.826.56, p-value< 0.001). Babies born through CS had more than two-fold risk for infection (aOR-2.06, 95\% CI, $1.48-2.87$, $\mathrm{p}$-value $<0.001)$ and babies who had birth asphyxia had more than three-fold risk for infection (aOR3.51, 95\% CI, 1.71-7.20, p-value $=0.001)($ Table 3$)$.

\section{Discussion}

Our finding suggesting that babies born to first time mothers were at high risk of neonatal infection is consistent with the study conducted in Nepal by Shah et al. which reported that there was high risk of neonatal infection in babies born to nulliparous mothers [20]. Similar findings were observed in another study conducted by Adatara et al. [21]. This may be related to pregnancy complications commonly present in young mothers [22]. It is possible that young mothers lack experiences in handling babies, so might have a poor hygienic practice during postnatal period, which could lead to infection [23].

Babies born through CS had significantly higher risk of having infection than those born through vaginal delivery. This finding is consistent with the study conducted by Rojas et al. which demonstrated a significant association of CS with neonatal infection [24]. The intra-operative procedure during CS with a lack of fully sterile conditions might have led to the increased risk of infection [25]. Furthermore, the indications for CS such as fetal distress, cord prolapse, prolonged or obstructed labor contributes to the increased risk for infection $[26,27]$. 
Table 3 Multi-variate and bi-variate analysis of the risk factor

\begin{tabular}{|c|c|c|c|c|}
\hline Variables & crude Odds Ratio (cOR) & $P$-value & adjusted Odds Ratio (aOR) & $P$-value \\
\hline Advantageous group (ref- disadvantageous group) & $1.34(1.11-1.62)$ & 0.002 & $1.28(1.03-1.60)$ & 0.028 \\
\hline 0 previous birth (ref- $\geq 1$ previous birth) & $1.59(1.31-1.92)$ & $<0.001$ & $1.64(1.30-2.06)$ & $<0.001$ \\
\hline No Antenatal check up (ref- with Antenatal check up) & $3.15(1.72-5.78)$ & $<0.001$ & $3.45(1.82-6.56)$ & $<0.001$ \\
\hline $\begin{array}{l}\text { Suspected maternal infection } \\
\text { (ref- no maternal infection) }\end{array}$ & $2.03(1.64-2.51)$ & $<0.001$ & $1.13(0.80-1.59)$ & $<0.001$ \\
\hline $\begin{array}{l}\text { Caesarean section } \\
\text { (ref- vaginal delivery) }\end{array}$ & $2.20(1.81-2.68)$ & $<0.001$ & $2.06(1.48-2.87)$ & $<0.001$ \\
\hline $\begin{array}{l}\text { Birth asphyxia } \\
\text { (ref- no birth asphyxia) }\end{array}$ & $3.77(2.05-6.91)$ & $<0.001$ & $3.51(1.71-7.20)$ & 0.001 \\
\hline
\end{tabular}

The findings in this study showed that babies with birth asphyxia had two-fold higher risk of neonatal infection. This is consistent with a study conducted by Getabelew et al. which demonstrated a three-fold increased risk of infection among babies who had birth asphyxia compared with those who did not [28]. Hospital acquired infections may occur when babies born with asphyxia are transferred to sick newborn care units for further management where the units are not in a sterile condition [29].

We also observed that babies of mothers who had no antenatal checkup by skilled providers had high risk of neonatal infection. This may be due to lack of counseling from the skilled providers for delivery preparations.

Our findings also showed that babies born to advantageous ethnic group had a higher risk of infection than those born to disadvantageous ethnic groups. In Nepal, the social and cultural practices relating to pregnancy care vary by ethnic group. Pregnant women from advantageous ethnic group have more restrictions in the hygiene practice than disadvantageous group, which might have led to risk for neonatal infection. Many cultural practices of advantageous groups like wrapping newborn with old clothes, applying oil to umbilical cord and poor breast feeding practices can result in neonatal infection. A study in a rural Nepal showed that the level of awareness among disadvantageous group is better than advantageous ethnic group [30].

\section{Methodological consideration}

There are some limitations in the study. The study did not analyse some of the risk factors associated with neonatal infections such as previous medical history and previous preterm births. Furthermore, the interviews conducted with the mothers may be exposed to recall bias. This study has many strengths, including that it is a sample of over 60,000 birth from 12 different hospitals. Therefore, the results of this study are likely to be representative of the hospital based incidence rate of neonatal infection in Nepal.

\section{Conclusion}

This study utilized data from a large cohort of births registered in public hospitals across Nepal to provide a better understanding of the neonatal infection from an epidemiological perspective. Findings from this study suggest that first time mothers, non-attendance at antenatal check-ups, CS and birth asphyxia are factors which increase the risk for neonatal infection. These findings suggest that there is a need to improve the intraoperative and post-operative environment to prevent infection of babies and mothers. Furthermore, improving care during the intrapartum period may reduce the risk for infection. Further research on what practices during the pregnancy in the advantageous ethnic group is needed to understand the link between neonatal infection and ethnicity in Nepal.

\section{Supplementary information}

Supplementary information accompanies this paper at https://doi.org/10. 1186/s13690-020-00424-Z.

Additional file 1. Estimated deliveries at the selected hospital 2015

\section{Abbreviations}

LMICs: Low- and middle-income countries; ANC: Antenatal care;

CSPro: Census and survey processing system; SPSS: Statistical package for the social sciences; aOR: Adjusted odds ratio

Acknowledgements

The authors would like to acknowledge the data collectors and Omkar Basnet at Golden Community.

\section{Authors' contributions}

SSB, AK, PP and AKS conceived and planned the study. SSB, JT and AKS performed the analysis. SSB prepared the first draft of the manuscript. SK, $L B B, P P$ and $R G$ reviewed the manuscript. All authors read and approved the final manuscript.

\section{Funding}

The study was funded Swedish Research Council, Sweden; Einhorn Family Foundation, Sweden and Laerdal Foundation for Acute Medicine, Norway. Open access funding provided by Uppsala University.

Availability of data and materials

The data will be made available on request. 


\section{Ethics approval and consent to participate}

Written informed consent were taken from the mothers before the interview and confidentiality on the information was maintained. The study was approved by Ethical Review Board of Nepal Health Research Council (reference number 26-2017).

\section{Consent for publication}

The dataset will be made available upon request.

\section{Competing interests}

The authors declare that they have no any competing interests.

\section{Author details}

${ }^{1}$ Golden Community, Lalitpur, Nepal. ${ }^{2}$ Department of Primary Care and Public Health, School of Public Health, Imperial College London, London, UK. ${ }^{3}$ Department of Community Health Sciences, Patan Academy of Health Sciences, Lalitpur, Nepal. ${ }^{4}$ School of Public Health \& Community Medicine, B P Koirala Institute of Health Sciences, Dharan, Nepal. ${ }^{5}$ Ministry of Health and Population, Government of Nepal, Ramshah Path, Kathmandu, Nepal. ${ }^{6}$ Department of Women's and Children's Health, Uppsala University, Dag Hammarskjölds väg 14B, Uppsala, Sweden.

\section{Received: 5 December 2019 Accepted: 24 April 2020}

Published online: 07 May 2020

\section{References}

1. UNICEF, WHO, World Bank and United Nations on Behalf of UN Inter-agency group for Child Mortality Estimation. Level and trend of Child Mortality 2019. New York: UNICEF; 2019.

2. Liu L, Oza S, Hogan D, Perin J, Rudan I, Lawn JE, Cousens S, Mathers C, Black RE. Global, regional, and national causes of child mortality in 2000-13, with projections to inform post-2015 priorities: an updated systematic analysis. Lancet. 2015;385(9966):430-40.

3. Fleischmann-Struzek C, Goldfarb DM, Schlattmann P, Schlapbach LJ, Reinhart K, Kissoon N. The global burden of paediatric and neonatal sepsis: a systematic review. Lancet Respir Med. 2018:6(3):223-30.

4. Amare D, Mela M, Dessie G. Unfinished agenda of the neonates in developing countries: magnitude of neonatal sepsis: systematic review and meta-analysis. Heliyon. 2019;5(9):e02519.

5. Ferreira RC, Mello RR, Silva KS. Neonatal sepsis as a risk factor for neurodevelopmental changes in preterm infants with very low birth weight. J Pediatr. 2014;90(3):293-9.

6. Adams-Chapman I, Stoll BJ. Neonatal infection and long-term neurodevelopmental outcome in the preterm infant. Curr Opin Infect Dis. 2006:19(3):290-7.

7. Stoll BJ, Hansen NI, Adams-Chapman I, Fanaroff AA, Hintz SR, Vohr B, Higgins RD. National Institute of child $\mathrm{H}$, human development neonatal research $\mathrm{N}$ : neurodevelopmental and growth impairment among extremely low-birth-weight infants with neonatal infection. JAMA. 2004:292(19):235765 .

8. Ministry of Health and Population Nepal. Nepal's Every Newborn Action Plan 2016-2030. Kathmandu: MoHP; 2016.

9. National Planning Commission Government of Nepal. Nepal Sustainable Development Goals: Status and Roadmap 2016-2030. Kathmandu: GON ; 2016

10. Kc A, Jha AK, Shrestha MP, Zhou H, Gurung A, Thapa J, Budhathoki S. Trends for neonatal deaths in Nepal (2001-2016) to project progress towards the SDG target in 2030, and risk factor analyses to focus action. Matern Child Health J. 2020;24(Suppl 1):5-14

11. Chapagain RH, Acharya R, Shrestha N, Giri BR, Bagale BB, Kayastha M. Bacteriological profile of neonatal Sepsis in neonatal intermediate care unit of central Paediatric referral Hospital in Nepal. J Nepal Health Res Counc. 2015;13(31):205-8

12. Shrestha G, Mulmi R, Joshi N, Shrestha PR. Prevalence of Sepsis and possible severe bacterial infection among neonates in Nepal. J Nepal Health Res Counc. 2018;16(1):1-5.

13. Yadav NS, Sharma S, Chaudhary DK, Panthi P, Pokhrel P, Shrestha A, Mandal PK. Bacteriological profile of neonatal sepsis and antibiotic susceptibility pattern of isolates admitted at Kanti Children's hospital, Kathmandu, Nepal. BMC Res Notes. 2018;11(1):301.
14. Kc A, Bhandari A, Pradhan YV, Kc NP, Upreti SR, Thapa K, Sharma G, Upreti S, Aryal DR, Dhakwa JR, et al. State of maternal, newborn and child health programmes in Nepal: what may a continuum of care model mean for more effective and efficient service delivery? I Nepal Health Res Counc. 2011;9(2):92-100.

15. Malqvist M, Pun A, Raaijmakers $H, K c$ A. Persistent inequity in maternal health care utilization in Nepal despite impressive overall gains. Glob Health Action. 2017;10(1):1356083.

16. Kc A, Ewald U, Basnet O, Gurung A, Pyakuryal SN, Jha BK, Bergstrom A, Eriksson L, Paudel P, Karki S, et al. Effect of a scaled-up neonatal resuscitation quality improvement package on intrapartum-related mortality in Nepal: a stepped-wedge cluster randomized controlled trial. PLoS Med. 2019;16(9):e1002900

17. Kc A, Bergstrom A, Chaulagain D, Brunell O, Ewald U, Gurung A, Eriksson L, Litorp H, Wrammert J, Gronqvist E, et al. Scaling up quality improvement intervention for perinatal care in Nepal (NePeriQIP); study protocol of a cluster randomised trial. BMJ Glob Health. 2017;2(3):e000497.

18. Subedi M. Caste system: theories and practices in Nepal. Himalayan J Sociol Anthropol. 2010;4:134-59.

19. Gerber A, Hofen-Hohloch AV, Schulze J, Groneberg DA. Tobacco smoke particles and indoor air quality (ToPIQ-II) - a modified study protocol and first results. J Occup Med Toxicol. 2015:10:5.

20. Shah GS, Budhathoki S, Das BK, Mandal RN. Risk factors in early neonatal sepsis. Kathmandu Univ Med J (KUMJ). 2006:4(2):187-91.

21. Adatara P, Afaya A, Salia SM, Afaya RA, Konlan KD, Agyabeng-Fandoh E, Agbinku E, Ayandayo EA, Boahene IG. Risk factors associated with neonatal Sepsis: a case study at a specialist Hospital in Ghana. ScientificWorldJournal. 2019;2019:9369051.

22. Soman M, Green B, Daling J. Risk factors for early neonatal sepsis. Am J Epidemiol. 1985;121(5):712-9.

23. Rosenstock S, Katz J, Mullany LC, Khatry SK, LeClerq SC, Darmstadt GL, Tielsch JM. Sex differences in neonatal mortality in Sarlahi, Nepal: the role of biology and environment. J Epidemiol Community Health. 2013;67(12):98691

24. Rojas MA, Efird MM, Lozano JM, Bose CL, Rojas MX, Rondon MA, Ruiz G, Pineros JG, Rojas C, Robayo G, et al. Risk factors for nosocomial infections in selected neonatal intensive care units in Colombia, South America. J Perinatol. 2005;25(8):537-41.

25. Mazimpaka C, Uwitonze E, Cherian T, Hedt-Gauthier B, Kateera F, Riviello R, El-Khatib Z, Sonderman K, Gruendl M, Habiyakare C, et al. Perioperative management and outcomes after cesarean section-a cross-sectional study from rural Rwanda. J Surg Res. 2019:245:390-5.

26. Harrison MS, Ali S, Pasha O, Saleem S, Althabe F, Berrueta M, Mazzoni A, Chomba E, Carlo WA, Garces A, et al. A prospective population-based study of maternal, fetal, and neonatal outcomes in the setting of prolonged labor obstructed labor and failure to progress in low- and middle-income countries. Reprod Health. 2015;12(Suppl 2):S9.

27. Adatara P, Afaya A, Salia SM, Afaya RA, Kuug AK, Agbinku E, AgyabengFandoh E. Risk factors for neonatal Sepsis: a retrospective case-control study among neonates who were delivered by caesarean section at the trauma and specialist hospital, Winneba, Ghana. Biomed Res Int. 2018;2018:6153501.

28. Getabelew A, Aman M, Fantaye E, Yeheyis T. Prevalence of neonatal Sepsis and associated factors among neonates in neonatal intensive care unit at selected governmental hospitals in Shashemene town, Oromia regional state, Ethiopia, 2017. Int J Pediatr. 2018:2018:7801272.

29. Perlman SE, Saiman L, Larson EL. Risk factors for late-onset health careassociated bloodstream infections in patients in neonatal intensive care units. Am J Infect Control. 2007;35(3):177-82.

30. Sanjel K, Onta SR, Amatya A, Basel P. Patterns and determinants of essential neonatal care utilization among underprivileged ethnic groups in Midwest Nepal: a mixed method study. BMC Pregnancy Childbirth. 2019;19(1):310.

\section{Publisher's Note}

Springer Nature remains neutral with regard to jurisdictional claims in published maps and institutional affiliations. 